Rosângela Benito; Carolina P. de Andrade;

Érica Aparecida de O. Fernandes; Alice da Silva;

Marcia Maria Antonio; Daniel B. O. Tejera

\title{
ANÁLISE QUALITATIVA DOS TRABALHOS RELACIONADOS À TEMÁTICA “LAZER E POLÍTICAS PÚBLICAS”, PUBLICADOS NOS ANAIS DO ENAREL, DE 1991 A $2008^{1}$
}

Recebido em: 23/07/2009

Aceito em: 11/11/2009

\begin{abstract}
Nelson Carvalho Marcellino ${ }^{2}$; Liana A. Romera ${ }^{3}$; Sérgio Barcelos $^{4}$; Cathia Alves ${ }^{5}$; Karina Sarto ${ }^{6}$; Rosângela Benito ; Carolina Paes de Andrade ${ }^{8}$; Érica Aparecida de Oliveira Fernandes $^{9}$; Alice da Silva ${ }^{10}$; Marcia Maria Antonio ${ }^{11}$; Daniel Bidia Olmedo Tejera ${ }^{12}$
\end{abstract}

Grupo de Pesquisa em Lazer (GPL) - UNIMEP Piracicaba - SP - Brasil

RESUMO: O presente trabalho é resultado de um estudo realizado pelo Grupo de Pesquisa em Lazer - GPL/UNIMEP, que teve por objetivo analisar a produção do conhecimento na área do lazer, a partir dos anais do Encontro Nacional de Recreação e Lazer - ENAREL. A metodologia adotada no trabalho foi do tipo qualitativo, a partir da pesquisa bibliográfica, tendo como método o estudo exploratório, realizado nos anais do referido evento no período de 1991 a 2008. O material que deu origem a este artigo é referente às análises textuais e temáticas de 194 trabalhos relacionados a "lazer e políticas públicas" apresentados nas edições do referido evento, desde 1991, na forma de comunicações orais, que foram tratadas a partir de abordagem qualitativa. Observouse que a qualidade dos trabalhos científicos assim como as ações e programas relacionados ao lazer apontaram o amadurecimento das reflexões com 0 desenvolvimento das edições do ENAREL, ao longo dos anos. Os resultados apresentados neste estudo procuram contribuir para a formação de banco de dados

\footnotetext{
${ }^{1}$ Pesquisa intitulada "A produção do conhecimento na área do lazer: uma análise sobre os anais do Encontro Nacional de Recreação e Lazer", desenvolvida pelos membros do Grupo de Pesquisas em Lazer - GPL, vinculado à Universidade Metodista de Piracicaba - UNIMEP.

${ }^{2}$ Livre Docente em Estudos do Lazer - UNIMEP/CNPq/GPL - marcelin@supernet.com.br

${ }^{3}$ Doutora em Educação Física, Docente da UNIMEP/ GPL - liromera@uol.com.br

${ }^{4}$ Doutorando em UTAD - Portugal, Professor e Coordenador do Curso de Educação Física do Centro Universitário do Planalto de Araxá - UNIARAXÁ / GPL - sergiobarcelos@ uniaraxavirtual.com.br

${ }^{5}$ Mestre em Educação Física. Docente da UNIARARAS/ GPL - cathiaal@,hotmail.com

${ }^{6}$ Mestre em Educação Física - GPL ka sarto@terra.com.br

${ }^{7}$ Mestre em Educação Física. GPL - rosangelabenito@yahoo.com.br

${ }^{8}$ Mestranda em Educação Física, pela UNIMEP / GPL - caru19@yahoo.com.

${ }^{9}$ Mestranda em Ed. Física, pela UNIMEP / GPL tiaxu2005@yahoo.com.br

${ }^{10}$ Bacharel em Educação Física pela UNIMEP/ GPL - aliceromualdo@yahoo.com.br

${ }^{11}$ Bacharel em Educação Física pela UNIMEP / GPL - mamantonio@unimep.br

${ }^{12}$ Licenciado em Educação Física / GPL - olmedo@,ig,com.br
} 
Rosângela Benito; Carolina P. de Andrade;

Érica Aparecida de O. Fernandes; Alice da Silva;

Marcia Maria Antonio; Daniel B. O. Tejera

referente ao tema, assim como para a organização histórica da trajetória dos estudos do lazer no Brasil.

PALAVRAS-CHAVE: Atividades de lazer. Políticas Públicas. Análise Qualitativa.

\section{QUALITATIVE ANALYSIS OF WORKS RELATED TO THE SUBJECT OF "LEISURE AND PUBLIC POLICIES" PUBLISHED IN THE ANNALS OF ENAREL, FROM 1991 TO 2008}

ABSTRACT: The present work is the result of a study performed by the Research Group on Leisure - GPL/UNIMEP, which aimed at analyzing the production of knowledge in the field of leisure through the annals of the National Meeting on Recreation and Leisure (ENAREL). The methodology adopted in the work was of qualitative type by means of literature research. The method employed was an exploratory study of the annals of the mentioned event, which occurred from 1991 to 2008. The material that originated this article refers to textual and thematic analyses of 194 works on "leisure and public policies" presented in the events' several editions, starting in 1991, in the form of oral communications, through a qualitative approach. The quality of the scientific works, as well as the actions and programs related to leisure, showed that reflections matured together with the development of Enarel's editions throughout the years. The results presented in this study are meant to contribute to the creation of a data bank on the subject, as well as to the historical organization of the studies on leisure in Brazil.

KEYWORDS: Leisure Activities. Public Policies. Qualitative Analysis.

\section{Introdução}

O ENAREL (Encontro Nacional de Recreação e Lazer) representa o evento nacional de caráter científico mais antigo voltado à produção de conhecimento sobre lazer no Brasil e comemorou, em 2008, sua vigésima edição. Podem ser encontradas nas publicações do evento o registro de grande parte dos estudos e projetos desenvolvidos na área do lazer, produzidos por alunos, pesquisadores e profissionais ligados às várias áreas de conhecimento que atuam ou estudam o contexto do lazer.

Sendo o ENAREL um encontro de grande mobilização para essa área, considerou-se de fundamental importância a análise dos estudos e ações relacionados ao 
Lazer, apresentados no referido evento, buscando compreender a sua evolução, no

Brasil, ao longo dos últimos vinte anos.

A pesquisa desenvolvida pelo GPL, intitulada "A produção do conhecimento na área do Lazer: uma análise sobre os anais do Encontro Nacional de Recreação e Lazer ENAREL" foi constituída dentro de uma subdivisão com três eixos temáticos, os quais nortearam os trabalhos dos grupos de interesse, a saber: meio ambiente, formação profissional e políticas públicas.

Este estudo dedicou-se à análise dos anais do referido evento, especificamente, no eixo temático de lazer e políticas públicas, dando ênfase às comunicações orais apresentadas e nele publicadas. A pesquisa tem por objetivo geral investigar as produções acadêmico-científicas veiculadas nas diversas versões dos anais do Encontro Nacional de Recreação e Lazer - ENAREL, as quais tenham um enfoque eminentemente interligado às linhas de pesquisa do Grupo de Pesquisa em Lazer GPL/UNIMEP. Dentre os objetivos específicos, a pesquisa visou desenvolver estudos exploratórios nos anais do ENAREL sobre a relação temática lazer e políticas públicas, focalizando os seguintes aspectos: tipo de trabalho, termos utilizados (palavras-chave), referencial teórico utilizado (autores/as), metodologias utilizadas, público-alvo e resultados da pesquisa.

\section{Lazer e políticas públicas}

Num primeiro momento, cabe esclarecer algumas questões concernentes ao caminho percorrido para a realização desta pesquisa. Primeiro, no que diz respeito ao termo "políticas públicas", optou-se por fazer uso de seu entendimento num sentido mais amplo, ou seja, utilizando-o para fazer referência a ações que partem não 
Nelson C. Marcellino; Liana A. Romera; Análise Qualitativa dos trabalhos Relacionados...

Sérgio Barcelos ${ }^{1}$; Cathia Alves; Karina Sarto ${ }^{1}$;

Rosângela Benito; Carolina P. de Andrade;

Érica Aparecida de O. Fernandes; Alice da Silva;

Marcia Maria Antonio; Daniel B. O. Tejera

exclusivamente da esfera governamental. Preferiu-se, para efeito de análise dos

trabalhos apresentados nas várias edições do ENAREL, entender o "público" de acordo

com as indicações de Ribeiro:

Na modernidade, é preciso distinguir na palavra público dois sentidos principais. Primeiro aquele em que ela se opõe a 'privado', e se faz sinônimo de bem comum. Isso não quer dizer 'estatal': pode haver uma esfera pública que não pertença ao Estado, por exemplo, a de uma associação ou entidade que não tenha por finalidade apenas o bem de seus donos (o chamado 'terceiro setor' [...]) (RIBEIRO, 2000, p.101-2).

Nesse sentido, a compreensão do significado de público estende-se, no presente trabalho, a outras esferas sociais que desenvolvem ações voltadas à comunidade e não se encontram vinculados à esfera do estado ou dos governos, seguindo assim a mesma linha de pensamento de Monteiro; Coimbra; Mendonça, que afirmam, sobre essa questão:

[...] há que repensar a relação entre Estado e políticas públicas. Acreditamos que estes termos não podem ser tomados como coincidentes, visto que os domínios do Estado e do público não se justapõem, não sendo natural à relação de sinonímia entre eles. Entendemos que o público diz respeito à experiência concreta dos coletivos de forças sempre em movimento (MONTEIRO; COIMBRA; MENDONÇA FILHO, 2006, p.11).

Assim, foram incluídos, na presente análise, trabalhos elaborados por outras esferas (sistemas corporativos, universidades públicas e particulares), e que tivessem como tema projetos ou propostas que almejassem o bem comum, ou ainda pesquisas sobre esta temática. O propósito aqui não é discutir a conceituação do termo; no entanto, o fato de ter optado, nesta pesquisa, por utilizar a visão ampliada de políticas públicas referida acima, justifica como relevante tal esclarecimento.

Para reforçar a inclusão das iniciativas corporativas, Pereira e Grau (1998), afirmam que as dificuldades de se distinguir o que é público do corporativo crescem 
Nelson C. Marcellino; Liana A. Romera; Análise Qualitativa dos trabalhos Relacionados...

Sérgio Barcelos ${ }^{1}$; Cathia Alves; Karina Sarto ${ }^{1}$;

Rosângela Benito; Carolina P. de Andrade;

Érica Aparecida de O. Fernandes; Alice da Silva;

Marcia Maria Antonio; Daniel B. O. Tejera

quando se considera que "ao defender interesses particulares, as organizações

corporativas podem também estar defendendo o interesse geral" (PEREIRA; GRAU, 1998, p. 9).

Também buscando o entendimento sobre política pública, Padilha (2004, p. 66) aponta a seguinte reflexão: “[...] pode-se pensar que ela deveria ser uma resposta e um compromisso do Estado em relação às demandas sociais nas diferentes áreas - o que entrelaça sociedade civil e o Estado".

Dessa forma, para que uma política pública seja efetiva é preciso ligar-se ao poder de estado e ao poder civil, sendo necessário que haja uma parceria entre esses elementos, uma união em busca de consolidação.

A respeito da política pública de lazer especificamente, Marcellino (2001) a descreve como um processo de mudanças que envolvem questões mais abrangentes, dentre as quais, destaca ser preciso reduzir a jornada de trabalho, sem diminuir os salários; uma política de transporte; uma política de reordenação de solo urbano, uma política tanto dos equipamentos como dos espaços, e ainda de moradia e seu entorno; conclui ainda o referido autor, ser preciso formar quadros de profissionais e voluntários que atuem de forma competente. Para Marcellino (2001), o lazer tem sua especificidade, mas não deve ser tratado de forma isolada, ou seja, é necessário valorizar todas as esferas de atuação humana.

Considerando a abrangência do tema, pode-se afirmar que muitos são os desafios que se apresentam quando se pensa na implantação de uma política pública de lazer, pois toda organização e ação planejada estarão comprometidas com o entendimento do lazer (BENITO; SAMPAIO, 2008). 
Deve ser ressaltado que, que para fins de planejamento, programação e promoção de ações no campo do lazer, os estudos de Dumazedier, bem como as propostas de Marcellino têm oferecido importante aporte teórico e metodológico para os profissionais que se debruçam na tarefa organizativa de políticas públicas da área (BENITO; SAMPAIO, 2007).

Para melhor compreensão do sentido do termo assumido neste estudo, vale ressaltar que o lazer é aqui considerado, conforme Marcellino (2008), como uma manifestação cultural, combinando os aspectos de tempo/espaço e atitude, podendo promover valores questionadores da ordem social dominante, influenciando e sendo influenciado pelo sistema, além de cooperar para mudanças de cunho moral e cultural; sendo portador de um duplo aspecto educativo, ampliando a abrangência de sua vivência, englobando descanso, divertimento e desenvolvimento.

Historicamente, as reflexões acerca do lazer passam a tomar corpo, no Brasil, por volta de 1950, no entanto, é a partir da década de 1970 que as investigações acadêmicas sobre o tema tiveram início de fato no país (MARCELLINO, 1996).

A construção de uma compreensão mais abrangente do termo lazer ocorre de forma lenta e gradativa. Embora este termo ainda seja acompanhado de preconceitos e concepções distorcidas, pôde-se inferir, a partir das publicações analisadas, que algumas transformações sinalizam um avanço no processo de evolução na compreensão do sentido do lazer, especialmente junto às iniciativas das administrações públicas responsáveis por sua promoção como direito social.

Essas modificações mesmo que ainda tímidas, podem proporcionar mudanças nas estratégias de ação dos poderes públicos, no sentido de efetivamente elaborar políticas de lazer que contemplem e atendam a população de maneira mais ampla, 
Nelson C. Marcellino; Liana A. Romera;

Sérgio Barcelos ${ }^{1}$; Cathia Alves; Karina Sarto ${ }^{1}$;

Análise Qualitativa dos trabalhos Relacionados...

Rosângela Benito; Carolina P. de Andrade;

Érica Aparecida de O. Fernandes; Alice da Silva;

Marcia Maria Antonio; Daniel B. O. Tejera

oportunizando acesso aos serviços de lazer, concretizando, dessa forma, um direito

social e não simplesmente a oferta de atividades monitoradas ou manipuladas por ações

com caráter eleitoreiro e assistencialista.

Por ser considerada uma área multi e interdisciplinar, os termos "lazer e políticas públicas" encontram-se associados a uma série de variáveis (cultura, meio ambiente, corpo, etc.). Dessa forma, nos casos dos anais em que os trabalhos apresentados sob a forma de comunicação oral se encontravam agrupados por temas variados associados ao lazer, optou-se por não analisar apenas aqueles identificados como pertencentes ao tema “Políticas Públicas”, quando esse tópico constava no sumário. Nestes casos, foi feito o levantamento percorrendo toda a publicação e, a partir dessa análise, realizada uma nova triagem, selecionando trabalhos agrupados nos diversos temas para serem analisados sob a perspectiva das políticas públicas.

O desenvolvimento de pesquisas e projetos por parte dos sistemas público governamental, não-governamental, corporativo e da iniciativa privada é de fundamental importância para que o lazer ocupe o espaço que lhe é devido enquanto direito assegurado pela Constituição Federal $^{13}$. A apresentação desses estudos e iniciativas, no ENAREL, além de levá-los ao conhecimento de um público mais amplo, pode desempenhar o papel de desencadeador de novos projetos.

Ao discutir política, público e lazer, o caminho torna-se complexo e repleto de lacunas. Este estudo procura contribuir para preenchê-las, ao relatar alguns aspectos retratados nas pesquisas sobre estes temas, assim como o modo que os mesmos têm sido

\footnotetext{
${ }^{13}$ Art. $6^{\text {o }}$ do Capítulo II - Dos Direitos Sociais: São direitos sociais a educação, a saúde, o trabalho, a moradia, o lazer, a segurança, a previdência social, a proteção à maternidade e à infância, a assistência aos desamparados, na forma desta Constituição.
} 
Nelson C. Marcellino; Liana A. Romera;

Análise Qualitativa dos trabalhos Relacionados...

Sérgio Barcelos ${ }^{1}$; Cathia Alves; Karina Sarto ${ }^{1}$;

Rosângela Benito; Carolina P. de Andrade;

Érica Aparecida de O. Fernandes; Alice da Silva;

Marcia Maria Antonio; Daniel B. O. Tejera

abordados, além de buscar um aprofundamento nas discussões veiculadas no meio

acadêmico sobre política pública de lazer.

\section{Metodologia}

A pesquisa tem uma natureza qualitativa, entendendo assim como Richardson (1989), que o método em questão pode descrever, analisar, compreender e classificar qualquer tipo de processo vivenciado, procurando aprofundamento em relação ao entendimento dos fenômenos.

A pesquisa foi realizada em duas etapas, sendo que a primeira teve um caráter de revisão bibliográfica em variadas fontes de dados, com o propósito de construir um embasamento teórico sobre as diversas temáticas a serem pesquisadas. A segunda etapa constituiu-se de um estudo exploratório nos diversos anais do ENAREL, sendo analisados todos os aspectos enfocados nos objetivos específicos, classificando o tipo de trabalho escrito e apresentado: mesa redonda, mesas temáticas, temas livres, pôsteres e outras categorias adotadas pela comissão científica de cada ENAREL.

Os instrumentos de coleta de dados foram caracterizados em dois tipos: um, geral, que possibilitou a unidade do projeto em questão, coletando informações gerais sobre as produções dos diversos anais; outro, específico, construído por cada subgrupo, de acordo com suas especificidades, contemplando os itens contidos nos objetivos específicos.

A organização dos dados coletados e analisados ocorreu por meio da escolha de indicadores qualitativos, versando sobre os inúmeros enfoques encontrados na pesquisa (temas, metodologias, etc), e agrupados de acordo com as características semelhantes e/ou convergentes. 
A análise foi feita de forma descritiva, permitindo esclarecer mais facilmente os dados encontrados.

Em relação à técnica de coleta de dados realizada no estudo exploratório foi utilizado o levantamento inicial das obras dos diferentes anais do ENAREL relacionados aos termos chaves lazer e políticas publicas, com a seleção do material realizada por meio da análise textual (SEVERINO, 2000), focalizando nessa fase o ano dos anais, o título dos trabalhos, os autores, a instituição, a paginação dos trabalhos nos anais e a área ligada à temática. Em seguida o material selecionado foi aprofundado por meio da análise temática (SEVERINO, 2000), a partir dos aspectos autores, instituições, palavras-chaves predominantes, tipo do material, discussão principal do texto em relação às políticas publicas, seguido das análises interpretativas e problematização, apresentando numa abordagem qualitativa, visando maior esclarecimento dos dados.

Na seqüência apresentamos os resultados das categorias de análise utilizadas na pesquisa.

\section{Análise e discussão dos trabalhos em lazer e políticas públicas - análise qualitativa 1. Características gerais dos trabalhos (tipos de pesquisa)}

Para fins de análise, foram levantados 194 trabalhos. Do total de trabalhos publicados e selecionados para este estudo, 176 correspondiam a comunicações orais; 12 relatos de experiências, no ano de 1995, pois neste ano só teve esse tipo de publicação referente ao tema. E em 2003 não teve comunicação oral, porém analisou-se 6 mesas temáticas.

Em relação às características gerais dos trabalhos, percebeu-se uma grande diversidade do material analisado, ou seja, foram encontradas pesquisas de campo, 
estudo de literatura apontando possíveis conclusões ou interpretações, relatos de experiências, estudos de casos, além de projetos pontuais (ações de impacto sem obrigatoriedade de continuidade, eventos esporádicos) e permanentes (eventos que passaram a fazer parte da agenda de projetos da instituição proponente).

Muitas pesquisas apresentavam-se ainda em andamento, quando da realização do encontro, sendo considerados trabalhos publicados, porém ainda não concluídos, que tinham por finalidade trazer a público resultados parciais relevantes, ou como fases de projetos amplos, ou ainda, estudos apresentados com o objetivo explícito de servirem de embasamento para futuras tomadas de decisão, no sentido de fomentar iniciativas em políticas públicas de lazer. Nesse último caso, enquadram-se principalmente as pesquisas bibliográficas sobre o tema e o inventário e a avaliação de equipamentos de lazer de uma localidade (sua apropriação por parte da população, sua estrutura, quantidade, etc.).

Notou-se que, nos anais de algumas edições do evento, nem todos os trabalhos publicados apresentaram a mesma estrutura. Alguns relatos de experiência, por exemplo, foram estruturados com os itens que caracterizam uma pesquisa científica, quais sejam, objetivos gerais, objetivos específicos, justificativa, metodologia e resultados. Tais itens, nesses casos, contêm dados referentes ao projeto em si (ex.: no caso da metodologia, a mesma refere-se às atividades realizadas nos projetos ou eventos relatados, local e horário, tipo de atividade, forma de divulgação, reuniões e elaboração de instrumentos de avaliação dos projetos/eventos, entre outros). Já em alguns estudos de caso, esses itens enquadravam-se no que se entende por pesquisa científica (ex.: o item metodologia descreve o tipo de pesquisa realizada, instrumentos de pesquisa, etc.). Observou-se que o uso dessa mesma estruturação/nomenclatura em trabalhos com focos 
tão distintos acaba por gerar uma confusão em relação ao significado dos itens que compõem um trabalho científico.

Foram detectados alguns relatos de experiência em que os autores não utilizaram tal terminologia, subdividindo algumas vezes o trabalho em itens com nomes variados, referentes ao conteúdo do qual tratariam. Tal impasse pareceu ter sido superado, conforme foi possível verificar nas publicações das últimas edições do evento, fato este provavelmente decorrente de um maior detalhamento e rigidez das exigências para a submissão de trabalhos, como também do amadurecimento dos próprios autores dos trabalhos submetidos.

Alguns trabalhos pautaram-se na aplicabilidade de ações das políticas desenvolvidas, e posterior avaliação dos mesmos, ou seja, políticas de lazer já consolidadas ou em consolidação, avaliação e discussão de políticas em andamento.

A análise dos trabalhos publicados assinalou maior ênfase na proposição de eventos, com predominância das ações voltadas aos projetos pontuais ou permanentes, prevalecendo à compreensão de lazer estreitamente vinculada à prática de atividades de caráter físico-esportivo.

\section{Visão /conceito de Política Pública divulgada pelos estudos}

Outro aspecto importante analisado refere-se à visão/conceito de política pública encontrada nos estudos. Em muitos trabalhos o conceito ou visão específica do que seria uma política pública de lazer não foi claramente explicitado.

As análises sinalizaram para uma grande quantidade de trabalhos apresentados que apontavam a preocupação com a superação de algumas barreiras sociais, acompanhada do comprometimento em superá-las através de atividades de lazer. 
Nelson C. Marcellino; Liana A. Romera;

Análise Qualitativa dos trabalhos Relacionados...

Sérgio Barcelos ${ }^{1}$; Cathia Alves; Karina Sarto ${ }^{1}$;

Rosângela Benito; Carolina P. de Andrade;

Érica Aparecida de O. Fernandes; Alice da Silva;

Marcia Maria Antonio; Daniel B. O. Tejera

Contudo, referiam-se a práticas eventuais que tão somente preenchiam o tempo livre das

pessoas sem fazê-las questionar ou proporcionar a "vivência de valores que pudessem

contribuir com mudanças de ordem moral e cultural" (MARCELLINO, 2008).

Pode-se detectar também que a idéia de política pública de lazer, tal como indicada por Marcellino (2008), (associada a uma política global que inclua transporte, espaço urbano, reordenação do tempo e estrutura de animação), ainda não se encontra amplamente firmada; existem traços dessa proposta, mas ainda são tímidas as iniciativas no âmbito governamental que sinalizem e concretizem as necessidades a serem contempladas para a efetivação ampla de políticas de lazer. Esse tipo de trabalho, apesar de ainda pouco presente, aponta para uma compreensão mais amadurecida das significações e abrangência da temática em questão, e representa um indicativo dos avanços colhidos a partir dos estudos do lazer no Brasil.

Nesse sentido, observou-se por meio das publicações analisadas que algumas delas buscam, através de projetos de lazer, proporcionar acesso, permanência e sucesso escolar; outros consideram que a simples instalação de equipamentos por si só caracterizará uma provável política de atendimento às necessidades de lazer da comunidade na qual o equipamento será inserido.

O que transparece em grande parte dos trabalhos analisados é uma representação de uma política de lazer como programa de ação que pode ser refletida de duas formas:

1. A política de lazer associada às práticas esportivas nas quais as pessoas buscam uma melhora de saúde, em busca de qualidade de vida;

2. A política de lazer assistencialista, como meio para promover a paz e a tranqüilidade, como um produto de ocupação do tempo, sem reflexão e posicionamento crítico. 
Nelson C. Marcellino; Liana A. Romera;

Sérgio Barcelos ${ }^{1}$; Cathia Alves; Karina Sarto ${ }^{1}$;

Análise Qualitativa dos trabalhos Relacionados...

Rosângela Benito; Carolina P. de Andrade;

Érica Aparecida de O. Fernandes; Alice da Silva;

Marcia Maria Antonio; Daniel B. O. Tejera

A idéia de política pública de lazer apresentou-se, na maioria dos casos, como

um conjunto de atividades nas quais o caráter educacional do lazer e sua perspectiva crítica e criativa raras vezes puderam ser verificados.

Em relação ao conceito operacional de lazer divulgado pelos estudos, observouse que o mesmo foi entendido, em muitos trabalhos como simples atividade ou como recreação, reduzido à prática pela prática, pautada na proposição de atividades físico esportivas.

As possibilidades de outras condições de vivência do lazer, ainda que somente contemplando os conteúdos físico-esportivos, conforme classificação de Dumazedier (1980b), como a de assistência a espetáculos, raras vezes foi verificada.

Diversos são os fatores que fazem com que o lazer seja compreendido de forma parcial e limitada, um deles encontra-se na associação que se faz do termo "lazer", às atividades recreativas e eventos de massa. Possivelmente, tal fato se dê, por conta da utilização exaustiva do termo para se referir a promoções de instituições que direcionam suas ações ao grande público. Com o reforço desta tendência pelos meios de comunicação de massa, tal fenômeno se torna ainda mais gritante.

Outro fator está relacionado aos próprios órgãos públicos, que utilizam a palavra "lazer" indiscriminadamente, sem obedecer a critérios definidos, gerando os tradicionais substantivos compostos: Secretaria/Departamento de Esporte, Turismo, Cultura, etc, e “Lazer" (MARCELLINO, 2002)

Ao longo da pesquisa, o entendimento do lazer surgiu de diferentes formas e dentre os trabalhos analisados, vários modos de referenciá-lo foram apontados, assim nomeou-se 3 características: 
Nelson C. Marcellino; Liana A. Romera;

Análise Qualitativa dos trabalhos Relacionados...

Sérgio Barcelos ${ }^{1}$; Cathia Alves; Karina Sarto ${ }^{1}$;

Rosângela Benito; Carolina P. de Andrade;

Érica Aparecida de O. Fernandes; Alice da Silva;

Marcia Maria Antonio; Daniel B. O. Tejera

1. Ação constante: pode ser entendida como ações que acontecem

semanalmente, de duas a três vezes por semana, geralmente ligadas a práticas esportivas, sendo parte delas voltadas para o modelo de esporte de alto rendimento (escolinhas);

2. Ação de suporte: são os eventos como, festivais, competições, jogos, campeonatos, geralmente ações ligadas à competitividade com objetivo de estimular os participantes à permanência nas práticas;

3. Ação de abalo: representam atrativos que envolvem um grande número de pessoas, como, shows, excursões, colônia de férias, viagens, passeios, um dia de cinema e teatro grátis; esse tipo de ação visa alcançar um grande número de pessoas, para posteriormente, em alguns casos, fazer uso dos eventos para divulgação de patrocínios e/ou partido político.

\section{Interesses do lazer mais presentes nos estudos apresentados}

Quanto à abordagem do lazer e seus diferentes conteúdos ${ }^{14}$, notou-se na descrição de grande parte dos trabalhos apresentados ao longo das diversas edições do ENAREL sobre as quais se debruçou esta pesquisa, a grande ênfase dada aos interesses físico-esportivos, fato este que reflete a associação restrita entre lazer e a realização de atividades, preferencialmente esportivas.

Outro fato que chamou a atenção foi que, em um dos trabalhos apresentados no ano de 2008 - que se propôs a analisar a visão de lazer apresentada nas propostas que almejavam serem contempladas com subsídios de um programa governamental -

\footnotetext{
14 Os interesses apresentados por Dumazedier (1980a) são: físico - esportivos, sociais, intelectuais, artísticos e manuais. Camargo (1992) acrescenta os interesses turísticos.
} 
Nelson C. Marcellino; Liana A. Romera;

Sérgio Barcelos ${ }^{1}$; Cathia Alves; Karina Sarto ${ }^{1}$;

Análise Qualitativa dos trabalhos Relacionados...

Rosângela Benito; Carolina P. de Andrade;

Érica Aparecida de O. Fernandes; Alice da Silva;

Marcia Maria Antonio; Daniel B. O. Tejera

verificou-se que, na prática, ainda se associa amplamente os projetos de lazer aos

conteúdos físico-esportivos.

Ainda nos trabalhos apresentados no congresso de 2008, percebeu-se, por outro lado, nas análises, a superação desta visão estreita que limita o lazer às práticas esportivas.

Pode-se entender, portanto, que, ao menos no que diz respeito às produções científicas voltadas para a área, já é possível perceber uma mudança da compreensão a respeito do lazer, no sentido de entendê-lo não só em sua relação com os interesses físico-esportivos, mas como possibilidade de desenvolvimento dos demais conteúdos que o compõem, de acordo com a classificação de Dumazedier (1980a). Contudo, parece ainda haver uma distância a ser superada entre a teoria e a prática nas iniciativas ligadas ao lazer e as políticas públicas.

Embora seja importante destacar a relevância social do esporte, que coletivamente contribui para a autonomia, solidariedade, cidadania, entre outros aspectos, além de vivências significativas, o que não se pode é considerá-lo como um elemento redentor, que redime as pessoas de todas as diferenças de classes sociais, como produto que conforma e castra. É necessária a vivência dos outros conteúdos culturais do lazer, que também contribuem para a sociedade (ALVES, 2007).

Pode também ser observado em alguns trabalhos que os demais interesses do lazer, como o artístico, o turístico e o social também foram contemplados nas atividades discutidas e apresentadas nas comunicações, porém, com menor freqüência e intensidade que os físicos esportivos.

O momento atual pode representar uma inversão nesta realidade, haja vista a presença de muitos trabalhos que apresentam uma compreensão mais ampla do lazer na 
Nelson C. Marcellino; Liana A. Romera;

Análise Qualitativa dos trabalhos Relacionados...

Sérgio Barcelos ${ }^{1}$; Cathia Alves; Karina Sarto ${ }^{1}$;

Rosângela Benito; Carolina P. de Andrade;

Érica Aparecida de O. Fernandes; Alice da Silva;

Marcia Maria Antonio; Daniel B. O. Tejera

última edição do evento. Tal fato, entretanto, só poderá ser afirmado em uma análise

futura que tenha como objeto as edições vindouras do evento.

Cabe salientar que somente o fato de detectar, entre os textos analisados, a menção aos diferentes interesses do lazer, não é suficiente para confirmar a presença efetiva dos mesmos nas políticas ou ações de lazer, ou seja, muitas vezes eles são citados para justificar a importância de implementação de políticas públicas que atendam o máximo de interesses do lazer, sem que se constate sua concretização nas ações implementadas. Deve ser ressaltado que os interesses intelectuais não foram mencionados nos trabalhos analisados, exceto no ano de 2008. Além disso, em alguns trabalhos os autores não especificaram o(s) interesse(s) do lazer contemplado(s) em seus projetos, pesquisas ou relatos de experiência.

\section{A participação de profissionais diversos e membros da comunidade na gestão de políticas de lazer}

Em relação à descrição dos profissionais atuantes na política de lazer, preponderou o profissional de Educação Física, o qual apareceu como o mais presente nos relatos. Detectou-se também a presença de outros profissionais como gestores, assistente social, paisagista, fotógrafos, pedagogos, coordenadores de centro comunitário, estagiários e bibliotecários, porém com menor freqüência com que se notou a menção aos educadores físicos. Tal constatação demonstra a gama de possibilidades que o lazer enseja, e sinaliza a amplitude desse setor, fortalecendo a idéia da interdisciplinaridade ser fator inerente à área.

Conforme apontado por Isayama (2002), em muitas situações, os profissionais do lazer são chamados de animadores. Para este autor, a atuação do animador no campo 
Nelson C. Marcellino; Liana A. Romera;

Sérgio Barcelos ${ }^{1}$; Cathia Alves; Karina Sarto ${ }^{1}$;

Análise Qualitativa dos trabalhos Relacionados...

Rosângela Benito; Carolina P. de Andrade;

Érica Aparecida de O. Fernandes; Alice da Silva;

Marcia Maria Antonio; Daniel B. O. Tejera

do lazer é muito importante, pois facilita o acesso aos seus interesses, possibilitando

maior desenvolvimento pessoal e social como uma de suas bases. $\mathrm{O}$ fato de o lazer abarcar uma grande diversidade cultural, e estar relacionado a outros aspectos da vida social, também é motivo de cuidado e atenção do animador.

O profissional precisa ter conhecimento e respeitar as diferenças, além de refletir sobre e ampliar sua visão de sociedade; um dos caminhos para que isso aconteça é que a linguagem para formação dos animadores seja a mesma, em todas as áreas, abordando todos os conteúdos com os mesmos princípios da animação, com igual valor de importância (ALVES; MARCELLINO, 2006).

Por conta das questões acima explicitadas, se faz necessária à formação de quadros profissionais de competências gerais e específicas, conforme ressaltado por Marcellino (2001), (2008), assim como a compreensão da importância do lazer para o desenvolvimento humano, ultrapassando a compreensão limitada que o vincula as atividades físicas, ou somente ao descanso e ao divertimento.

A respeito da formação do quadro de profissionais e a qualidade dos serviços oferecidos, Marcellino et al ressaltam:

Nessa perspectiva, a qualificação do quadro de pessoal que atua no campo do lazer independentemente do tipo de equipamento (tipologia. dimensões, capacidade, composição das instalações) torna-se ponto fundamental para a qualidade de serviços prestados nessa área (MARCELLINO et al, 2007, p.23).

Em relação à visão do senso comum que concebe o profissional de lazer como aquele a quem cabe a tarefa de entreter o público, distrair, alegrar, Isayama (2002) adverte que este profissional ainda é compreendido como um agente que tem por função ajudar as pessoas a esquecerem seus problemas cotidianos e, para tal, lança mão de jogos, brincadeiras e outras recreações e dinâmicas. 
Nelson C. Marcellino; Liana A. Romera;

Análise Qualitativa dos trabalhos Relacionados...

Sérgio Barcelos ${ }^{1}$; Cathia Alves; Karina Sarto ${ }^{1}$;

Rosângela Benito; Carolina P. de Andrade;

Érica Aparecida de O. Fernandes; Alice da Silva;

Marcia Maria Antonio; Daniel B. O. Tejera

Quanto à participação popular, grande parte dos projetos publicados, mencionou

atender a comunidade, mas poucos relataram a participação da mesma na elaboração, no processo de construção da proposta de política de lazer.

A pesquisa demonstrou que a comunidade de maneira geral é a mais contemplada, porém em poucos trabalhos foi explicitada claramente a comunidade (idosos, adultos, jovens, adolescentes e crianças). Não foi possível detectar qual é a faixa etária mais atendida pelas pesquisas. No entanto, algumas publicações declararam suas preocupações em atender os trabalhadores em geral; como também crianças, adolescentes e jovens universitários, perfazendo o publico alvo mencionado como atendido pelas intervenções.

A participação popular aparece timidamente como uma perspectiva de elaboração de políticas públicas no sentido de diagnosticar os interesses da população e permitir o envolvimento da mesma no planejamento, execução e avaliação das ações da política implantada ou ainda em planejamento para futura implantação.

Esta participação se torna extremamente importante quando pautada como uma ação comunitária que leva em conta a necessidade do conhecimento da situação, ou seja, a realidade, interesses e aspirações da população; participação efetiva no planejamento, organização e avaliação das ações; integração com órgãos e instituições locais, em busca de apoio político ou de recursos para manutenção e ampliação da ação (MARCELLINO, 1996).

Em vários trabalhos foi possível notar a compreensão do quão importante é a capacitação do público-alvo no sentido de torná-lo mais atuante nos processos de construção e desenvolvimento de iniciativas na área do lazer. Percebe-se, nesses casos, a consciência da importância do duplo aspecto educativo do lazer - qual seja a 
Nelson C. Marcellino; Liana A. Romera;

Análise Qualitativa dos trabalhos Relacionados...

Sérgio Barcelos ${ }^{1}$; Cathia Alves; Karina Sarto ${ }^{1}$;

Rosângela Benito; Carolina P. de Andrade;

Érica Aparecida de O. Fernandes; Alice da Silva;

Marcia Maria Antonio; Daniel B. O. Tejera

educação pelo e para o lazer (MARCELLINO, 2002) - por parte dos responsáveis pela

concepção dos projetos, uma vez que contempla em suas propostas esse segundo aspecto, tão freqüentemente negligenciado em iniciativas que se propõem a tornar concreto o lazer como direito dos cidadãos. Observou-se em alguns relatos a preocupação em possibilitar que os participantes superem o patamar conformista e atinjam um nível crítico e criativo em suas práticas de lazer.

\section{Parceria com outras secretarias ou órgãos}

Outro ponto a se destacar nos trabalhos de política pública de lazer refere-se à relação estabelecida entre as secretarias das administrações em torno do lazer. É preciso considerar novamente que, para que uma política de lazer se consolide, não basta somente à participação da secretaria de esporte e cultura de maneira isolada. As demais secretarias que compõem um governo são, de modo geral, elementos importantes acerca da intersetorialidade do lazer e podem desenvolver ações que combatam a baixa ressonância social do mesmo.

As pesquisas demonstram pouca relação entre as diferentes secretarias como também sua efetiva participação nas ações relatadas. Observou-se, ainda em relatos isolados a participação da secretaria do turismo, do esporte e da cultura. E em poucos casos, a presença das secretarias de urbanismo e transporte, da saúde e assistência social, e do meio ambiente, o que já demonstra algum progresso para a difusão do lazer, e seu entendimento.

Somente a partir das publicações de 1993, é que se pode perceber um crescente avanço da relação do lazer com outras secretarias. Houve maior participação em muitos 
Nelson C. Marcellino; Liana A. Romera;

Sérgio Barcelos ${ }^{1}$; Cathia Alves; Karina Sarto ${ }^{1}$;

Análise Qualitativa dos trabalhos Relacionados...

Rosângela Benito; Carolina P. de Andrade;

Érica Aparecida de O. Fernandes; Alice da Silva;

Marcia Maria Antonio; Daniel B. O. Tejera

trabalhos, com parcerias da secretaria de esporte, com Universidades e também com o sistema $\mathrm{S}^{15}$.

Observou-se que o sistema com participação mais expressiva foi o público governamental (que engloba as universidades públicas e as secretarias de governo), com 130 trabalhos inscritos dentro da referida temática, seguido pelo setor privado (que inclui as universidades privadas), com 34 trabalhos. O sistema corporativo (que inclui o sistema S) participou com 12 trabalhos na área. E em 18 trabalhos não foi identificado parceria.

Os dados encontrados demonstraram que ainda participam das políticas de lazer, prioritariamente os órgãos governamentais, as instituições de ensino superior e os SESC (Serviço Social do Comércio) e SESI (Serviço Social da Indústria).

Tais resultados sugerem a busca de novas possibilidades de discussão das políticas de lazer visando ampliar a participação de profissionais e setores envolvidos.

Na análise dos Anais do ano de 1999, especificamente, constatou-se que a maior parcela dos trabalhos apresentados em "Lazer e Políticas Públicas" foi de autoria do setor público governamental (prefeituras e suas secretarias - do Esporte e Lazer, do Esporte, Recreação e Lazer, da Educação, da Saúde, do Meio Ambiente), sendo alguns deles resultado de parcerias entre duas ou mais secretarias, além das universidades públicas.

Um dos estudos relata uma ação isolada na cidade de Santos - SP na década de 1990; que uma vez por mês não cobrava tarifas de transporte de ônibus urbano, na tentativa de promover o acesso da população às praias e outros espaços e equipamentos de lazer. A não cobrança de passagem de ônibus ocorria principalmente em datas

\footnotetext{
${ }^{15}$ Sesi e Sesc foram as instituições desse tipo mais presentes.
} 
Nelson C. Marcellino; Liana A. Romera;

Análise Qualitativa dos trabalhos Relacionados...

Sérgio Barcelos ${ }^{1}$; Cathia Alves; Karina Sarto ${ }^{1}$;

Rosângela Benito; Carolina P. de Andrade;

Érica Aparecida de O. Fernandes; Alice da Silva;

Marcia Maria Antonio; Daniel B. O. Tejera

comemorativas como dia das mães, dos pais e das crianças. Essa ação representa uma

tentativa significativa de democratização de acesso ao lazer, ainda que se dê em datas

específicas. Nesse sentido, as poucas possibilidades descritas pelos trabalhos apontaram

para uma falta de estruturação das ações ligadas à política de democratização de lazer.

Marcellino (1996) atenta para o fato de que é necessário considerar os limites da Administração Pública Municipal, o que significa que a questão do lazer só pode ser entendida na totalidade da ação humana, abrangendo, para além das questões ligadas ao poder executivo, outras ações como a diminuição da jornada de trabalho, ocupação do solo urbano, etc., conforme mencionado anteriormente, que representam temas importantes que devem compor a agenda de discussões relativas às políticas de lazer.

Em se tratando de políticas públicas, as parcerias são tão importantes quanto necessárias, visto que, justamente pelo fato de serem públicas, devem envolver o maior número de atores sociais, com vistas a chegar o mais próximo possível da satisfação dos interesses da comunidade e superação das carências sociais.

Cabe inicialmente às esferas governamentais, mas não somente a elas, incentivar e participar das discussões e ações que envolvam a questão do lazer de modo amplo, junto aos órgãos, secretarias, setores, clubes de serviços e instituições não governamentais e do terceiro setor que constituem a sociedade civil e almejam uma política de lazer mais democrática.

\section{Considerações Finais}

A análise dos trabalhos aqui apresentados, com ênfase na relação entre lazer e políticas públicas, publicados nos anais das várias edições do ENAREL, fornece 
Nelson C. Marcellino; Liana A. Romera;

Sérgio Barcelos ${ }^{1}$; Cathia Alves; Karina Sarto ${ }^{1}$;

Análise Qualitativa dos trabalhos Relacionados...

Rosângela Benito; Carolina P. de Andrade;

Érica Aparecida de O. Fernandes; Alice da Silva;

Marcia Maria Antonio; Daniel B. O. Tejera

subsídios para a construção de um panorama geral sobre esta temática nas diversas

regiões do país.

A discussão teórica a respeito de temas pertinentes, os estudos de caso, o inventário de práticas existentes, da estrutura de lazer e o diagnóstico da realidade das políticas públicas são todos trabalhos que em muito contribuem para o incremento de iniciativas na área.

Sugerem ainda novas possibilidades de estudos, os quais podem buscar embasamento nos dados colhidos nas pesquisas ou se espelhar nos modelos adotados nas mesmas e serem aplicados em outras localidades.

A participação crescente de universidades como fomentadores na produção de conhecimento na área, no sentido de analisar a realidade existente, apontar caminhos possíveis e fornecer subsídios importantes - tanto dados teóricos quanto dados estatísticos e qualitativos relacionados ao lazer - faz-se notar e leva a concluir que estudos preocupados em contribuir para uma melhoria na qualidade das políticas públicas de lazer vêm ganhando espaço entre os pesquisadores da área.

Ademais, pode ser observado, de modo gradativo, na linha do tempo desses vinte anos que demarcaram as análises do presente estudo, o amadurecimento dos profissionais e pesquisadores da área do lazer que, desenharam uma trajetória crescente da ampliação do entendimento acerca do lazer, das possibilidades que o mesmo carrega, e das necessidades da interdisciplinaridade exigidas.

As análises aqui apresentadas confirmam ainda que, embora os estudos do lazer sejam recentes no Brasil, conforme anteriormente mencionado por Marcellino, ganharam força, especialmente nos últimos dez anos, coincidindo com o aumento no 
número de cursos de especialização e atualização na área do lazer, em diversas

localidades do país, como também das publicações específicas do tema.

A análise dos trabalhos quer tenham sido eles relatos de experiências de ações e programas, ou resultados parciais ou finais de pesquisas científicas, contribuíram de forma significativa, para que se pudesse esboçar um panorama, ainda que inicial, da atual situação das políticas públicas de lazer no Brasil.

Acredita-se que os resultados deste estudo, possam representar um esforço inicial no sentido da formação de um amplo banco de dados sobre políticas públicas de lazer no Brasil, relacionadas e apresentadas durante os vinte anos do ENAREL.

\section{REFERÊNCIAS}

ALVES, C; MARCELLINO, N, C. Lazer no espaço urbano: Transversalidade e Novas Tecnologias. Champagnat: Curitiba, 2006, p. 267-277.

ALVES, C. O papel do profissional de Educação Física como intermediário entre o adulto e o lúdico. Dissertação (Mestrado) - Unimep, Piracicaba, 2007.

BENITO, R; SAMPAIO, T. M. V. A disseminação do esporte e lazer em Sorocaba. In: FONTOURA, Paula, (Org.). Pesquisa em Educação Física, Jundiaí, v. 7, n. 1, 2008, p. $29-36$.

A influência da Associação Cristã de Moços na disseminação do esporte e lazer em Sorocaba. Dissertação (Mestrado) - UNIMEP, Piracicaba, 2007.

BRASIL. Constituição (1988). Constituição da República Federativa do Brasil, 1988. Brasília: Senado Federal; Centro Gráfico, 1988.

CAMARGO, L, O. O que é lazer. 3. ed. São Paulo: Brasiliense, 1992.

DUMAZEDIER, J. Sociologia empírica do Lazer. São Paulo: Sesc, 1980a.

. Valores e conteúdos culturais do lazer. São Paulo: Sesc, 1980b.

ENCONTRO NACIONAL DE RECREAÇÃO E LAZER, 3., 1991, Brasília, Anais... Brasília, 1991. 
Nelson C. Marcellino; Liana A. Romera; Análise Qualitativa dos trabalhos Relacionados...

Sérgio Barcelos ${ }^{1}$; Cathia Alves; Karina Sarto ${ }^{1}$;

Rosângela Benito; Carolina P. de Andrade;

Érica Aparecida de O. Fernandes; Alice da Silva;

Marcia Maria Antonio; Daniel B. O. Tejera

ENCONTRO NACIONAL DE RECREAÇÃO E LAZER, 4., 1992, Rio de Janeiro,

Anais... Rio de Janeiro, 1992.

ENCONTRO NACIONAL DE RECREAÇÃO E LAZER, 5., 1993, Bertioga, Anais... Bertioga: SESC, 1993.

ENCONTRO NACIONAL DE RECREAÇÃO E LAZER, 6., 1994, Brasília, Anais... Brasília: DEFER, 1994.

ENCONTRO NACIONAL DE RECREAÇÃO E LAZER, 7., 1995, Recife. Anais... Recife, 1995.

ENCONTRO NACIONAL DE RECREAÇÃO E LAZER, 8., Porto Alegre, Anais... Porto Alegre, 1996.

ENCONTRO NACIONAL DE RECREAÇÃO E LAZER, 9., Belo Horizonte, Anais... Belo Horizonte, 1997.

ENCONTRO NACIONAL DE RECREAÇÃO E LAZER, 10, CONGRESSO MUNDIAL DO LAZER, 05, 1998, São Paulo. Anais... São Paulo, 1998.

ENCONTRO NACIONAL DE RECREAÇÃO E LAZER, 11., 1999, Foz do Iguaçu, Anais... Foz do Iguaçu, 1999.

ENCONTRO NACIONAL DE RECREAÇÃO E LAZER, 12., 2000, Balneário Camboriu, Anais... Balneário Camboriu, 2000.

ENCONTRO NACIONAL DE RECREAÇÃO E LAZER, 13., 2001, Natal, Anais... Natal, 2001.

ENCONTRO NACIONAL DE RECREAÇÃO E LAZER, 14., 2002, Santa Cruz do Sul. Anais... Santa Cruz do Sul, 2002.

ENCONTRO NACIONAL DE RECREAÇÃO E LAZER, 15., 2003, Santo André, Anais... Santo André, 2003.

ENCONTRO NACIONAL DE RECREAÇÃO E LAZER, 16., 2004, Salvador, Anais... Salvador, 2004.

ENCONTRO NACIONAL DE RECREAÇÃO E LAZER, 17., 2005, Campo Grande, Anais... Campo Grande, 2005.

ENCONTRO NACIONAL DE RECREAÇÃO E LAZER, 18, 2006, Curitiba, Anais...Curitiba, 2006.

ENCONTRO NACIONAL DE RECREAÇÃO E LAZER, 19., 2007, Recife, Anais... Recife, 2007. 
Nelson C. Marcellino; Liana A. Romera;

Sérgio Barcelos ${ }^{1}$; Cathia Alves; Karina Sarto ${ }^{1}$;

Análise Qualitativa dos trabalhos Relacionados...

Rosângela Benito; Carolina P. de Andrade;

Érica Aparecida de O. Fernandes; Alice da Silva;

Marcia Maria Antonio; Daniel B. O. Tejera

ENCONTRO NACIONAL DE RECREAÇÃO E LAZER, 20., 2008, São Paulo, Anais... São Paulo, 2008.

ISAYAMA, H, F. Recreação e Lazer como integrantes de currículos dos cursos de graduação em Educação Física. 2002. Tese (Doutorado) - Departamento de Educação Física, Unicamp, Campinas, 2002.

Marcellino, N, C. (Org.). Políticas Públicas Setoriais de Lazer: O papel das prefeituras. Campinas: Autores Associados, 1996.

Lazer e Esporte: Políticas Públicas. Autores Associados: Campinas, 2001.

2002.

. Estudos do lazer: uma introdução. 3. ed. Campinas: Autores Associados,

. (Org.). Políticas Públicas de Lazer. Campinas: Alínea, 2008.

. et al. Políticas públicas de lazer: formação e desenvolvimento de pessoal. Curitiba: Opus, 2007.

MONTEIRO, Ana; COIMBRA, Cecília; MENDONCA FILHO, Manoel. Estado democrático de direito e políticas públicas: estatal é necessariamente público?. Psicol. Soc., Porto Alegre, v. 18, n. 2, ago. 2006 . Disponível em: $<$ http://www.scielo.br/scielo.php?script=sci_arttext\&pid=S0102-

$71822006000200002 \& \operatorname{lng}=$ pt\&nrm=iso $>$. Acesso em: 05 fev. 2009. Doi: $10.1590 / \mathrm{S} 0102-71822006000200002$.

PADILHA, V. Apontamentos para um estudo crítico sobre políticas públicas de lazer. Licere, Belo Horizonte, v.7, n.1, 2004.

PEREIRA, L. C. B; GRAU, N. C. Entre o estado e o mercado: O público não-estatal. In: O público não-estatal na reforma do Estado. Caracas: CLAD; Paidós, 1998.

RIBEIRO, R. J. A sociedade contra o social: o alto custo da vida pública no Brasil. São Paulo: Companhia das Letras, 2000.

RICHARDSON, R. J. Pesquisa Social: métodos e técnicas. São Paulo: Atlas, 1989.

SEVERINO, A, J. Metodologia do trabalho científico. São Paulo: Cortez, 2000.

\section{Endereço dos Autores:}

Grupo de Pesquisa em Lazer (GPL)

Piracicaba - SP

Endereço Eletrônico: 1iromera@uol.com.br ou marcelin@supernet.com.br 